\title{
Unpacking gendered aspects of employment precarity in the UK academia
}

\author{
Olga Y. Rotar
}

Postdoctoral Research Fellow, Centre for Institutional Studies, HSE University, Moscow, Russia, e-mail: orotar@hse.ru.

\begin{abstract}
Non-standard employment is becoming increasingly prevalent in UK academia, as tenured opportunities diminish, and university employment practices adapt to a changeable and commercialised labour market. However, little is known about gendered aspects of UK precariat. This study analyses HESA data for the six-year period, from 2014/2015 to 2019/2020 academic years, to track distribution of part-time, fixed-term, hourly-paid and zero-hours employment among university staff of different seniority levels and academic employment functions.
\end{abstract}

Data shows that, during the considered period, there was no rise of part-time employment in UK academia for the considered period. Part-time employment is prevalent among male academics in senior positions, and among female academics in non-senior positions. Regarding the term of employment, the proportion of males employed full-time and on a fixed-term basis is higher than that for females. This trend is consistent for the whole considered period. Yet it can be noticed that the proportion of males employed on such contracts has slightly decreased, whilst the proportion of females working full-time on fixed-term conditions increased. Approximately the same number of academics of both genders, working both full-time and part-time, employed on hourly paid basis. 
The study findings suggest that, despite the dominant discourse that female academics are more affected by precariat, the nuanced analysis of the HESA data shows that non-standard employment is widespread for both genders, and its spread is not even among academics of various levels of seniority and academic functions, and across different contract terms and modes.

Keywords: academic labour market, precarity, precariat, UK academia, gender, HESA

\section{Highlights}

- There was no rise of part-time employment in UK academia between 2014/2015 and 2019/2020 academic years.

- Part-time employment is prevalent among male academics in senior positions, and among female academics in non-senior positions.

- For the considered period, the proportion of males employed full-time and on a fixedterm basis was consistently higher than that for females.

- More males are employed on salaried contracts, and approximately the equal number of academics of both genders employed on hourly paid basis.

- In 2019/2020 academic year, among the total of 3420 academics employed on a zerohour contract, there were $54 \%$ of female and $46 \%$ male academics

\section{Introduction}

In academia, non-standard, part-time or temporary employment is often referred to as precariat (Blackham, 2020), and associated with lack of employee security and protection, and poor financial compensations. In the UK, debates on precarity have gained visibility after a number of publications by Standing (2011, 2014), media publicity around the issue and union campaigns against zero-hour contracts. Despite such developments, the precarious group of academics remained largely invisible to the UK Higher Education Statistics Agency (HESA) until 2017, when questions on hourly-paid and zero-hours contracts were included into the survey.

Over the years, the development of precariousness in the UK did not have a clear route. Bryson and Barnes (2000) and Bryson (2004) emphasised that one particularly large group of 
precarious academics are those employed on fixed terms. They pointed out that female academics were more likely to remain on fixed-term contracts, whereas male academics are more likely to get a permanent academic post as their first job. Furthermore, Bryson and Barnes (2000) found that "for those on fixed-time contracts, women had both more contracts and shorter contracts than men" (p. 196).

HESA data demonstrates that the transition from fixed-term to permanent employment is difficult for both sexes. Yet, past research provides evidence that female academics are in a more disadvantaged position than men (Bryson, 2004). Bryson (2004) estimated that "relatively more men than women benefited from gaining an academic post directly from being a student" and "had more secure forms of temporary contract, such as rolling contracts, entering contracts staff ranks at a higher level, transition from contract to a permanent post, promotion within the lecturing scale" (p.198). Conversely, women on fixed-term employment on average spent longer on that form of contract and "experienced more changes" (Bryson, 2004, p. 198) in their working conditions. Women appeared to be more constrained in their ability to take up more secure alternatives and more than men see fixed-term contracts as a major barrier to career progression (Bryson, 2004).

The University and College Union (UCU) has recently identified a larger range of contractual forms that might be used in precarious work situations in the UK, including part-time, fixedterm, zero-hours and hourly-paid contracts (UCU, 2018). Lopes and Dewan (2015) distinguished four features of non-standard employment in the UK: "precarity, exploitation, lack of support, and lack of career progression" (p. 32). They reported that insecure conditions implied not only physical but also emotional consequences, e.g., participants were not able to make plans for the future, could not access protection or benefits available for permanent staff, and were struggling to claim other rights, such as housing benefits and tenancy agreements (Lopes \& Dewan, 2015, p. 32). Loveday (2018) explored the experience of UK academics working on fixed-term contracts and uncovered a high level of anxiety among them. She argued that "as HE undergoes a process of marketisation, and the teaching and research activities of academics are increasingly measured and scrutinised, the contemporary academy appears to be suffused with anxiety" and describes the stage of temporary academic staff as "neurotic" (Loveday, 2018, p. 154). Concern has been raised about a particular form of contract called 'zero-hour contracts', under which no specific working hours or pay are guaranteed, with workers staying at home until their employer calls them (Lang et al., 2013, p. 18). 
Digitalisation also contributes to the spread of a model where teachers are hired on short-term contracts to develop online courses, which then become the property of universities (Slobodskaya, 2018). This practice became especially relevant in the context of the COVID19 pandemic. On one hand, the introduction of online education into the wider HE system provides flexibility that allows academics to carry out teaching activities at a convenient place and time. On the other hand, it may impact workload without appropriate remuneration, since online learning technologies not only require time to adapt to but also lead to the increase in the number of students.

The expansion of the administrative staff responsible for control and strategic university development, and an introduction of the mechanism for evaluating the effectiveness of the work of research and teaching staff reflects the transition to the new academic marketplace. The emergence of non-standard contracts allows HEIs' managers to respond to changes in the demand for educational programs that have been especially turbulent during the pandemic, and reduce the costs associated with wages and social benefits of employees. Additionally, the global massification and increased accessibility of higher education resulted in an increase of university graduates, potential members of the precariat.

The issues discussed above have had significant implications for the academic labour market: decreasing morale and salaries, less autonomy, work intensification, and increased job insecurity (Bryson \& Barnes, 2010). To date, research on unequal or insecure working conditions among academics has been shaped by the broader discussion on gender equality in academia, with the strong focus on promotional opportunities for women (Deem, 2003; Fritsch, 2015; Morley, 2013; O’Connor, 2014). Others have explored labour market structures and mobility requirements in relation to parenting and the retention of early career researchers (Ackers \& Gill, 2005). Although it is suggested that female academics may benefit from fixedterm contracts, and that they show a stronger preference towards them (Bryson, 2004), the long history of disadvantage of female academics globally adds complexity to the issue. There is little attention to gender differences among precarious employees in academia, and how the gender gap of the precarious labour force is changing over time.

By drawing on the available statistical data obtained from HESA, this study aims i) to map the dynamics of part-time and fixed-term employment contracts in the UK academia over a fouryear period from 2014/2015 to 2019/2020 academic years, with a particular focus on gender 
differences; and ii) to analyse a distribution of hourly-paid and and zero-hours contracts in the 2019/2020 academic year. The following research questions are posed:

1. What is the pattern of distribution of part-time employment among UK academics of different gender?

2. What is the pattern of distribution of fixed-term employment contracts among UK academics of different gender?

3. What groups of academics were employed on hourly-paid and zero-hour employment contracts in the 2019/2020 academic year?

This paper is organised in the following way. First, I set the definition of precarious working conditions used in this study. Then, I explore what is known about the precariat and discuss the examples of predominant forms of precarious employment in the UK academia. Next, the study introduced a research methodology. Following that are the analysis and discussion of the research results. Finally, I summarise the study findings and contribution in the conclusion, along with the limitations of the research and its future directions.

\section{Literature review}

\section{The notion of precariousness}

The spread of fixed-term, part-time and zero-hour employment conditions have become a labour market issue in academia, with the growth of research on the insecure conditions of academics across the world (see studies Santiago \& Carvalho (2008) in the Portugal context, Pintos \& Aguilera (2013) in the Spanish context; Blackham (2020) in the Australian context). Data show that in the US, $75.5 \%$ of academics are non-tenure-track, whereas in Australia, there are around 84,000 casual academics representing over 50\% of all academic staff in Australian Higher Education (HE) (Blackham, 2020). Thus, precarious working conditions are becoming a predominant form of employment globally.

In the UK, precarious work appears to be prevalent in higher education too. Blackham (2020) found that four high ranking UK universities employ over $80 \%$ of academic staff on fixed-term 
and part-time contracts (e.g., in the University of Oxford, $76.1 \%$ of academic staff employed on such contracts).

A precariat was described by Standing (2011) as a condition that implies different forms of insecurities, including financial and social. The notion of precariousness was first introduced in 1963 by Pierre Bourdieu, and used in 1989, by Rodgers and Rodgers, to refer not only to the threat of employment insecurity, but also to the associated risk of poverty (Olsthoorn, 2014). Vulnerability and insecurity were central to the discussion of precarious employees in the early works of scholars (see Kalleberg, 2011; Vosko, 2006).

In the recent literature, all types of non-standard work, also characterised by a high degree of uncertainty, are commonly referred to as precarious work (Maiti, 2012; Hewison \& Kalleberg, 2013; Benach et al., 2016; Vives, Lopez \& Benach, 2020). Precarious work is discussed as a multidimensional problem that is not only presented in the non-standard form of employment relationships, but also associated with the "employment insecurity, income inadequacy, and lack of rights and protection" (Kreshpaj et al., 2020, p. 235). There is an opinion that academics, working in non-standard conditions, such as zero-hour contracts, part-time and other nonstandard forms of employment, experience a higher degree of uncertainty than their tenured colleagues. Furthermore, they are seen as less sheltered from economic instability. As Maiti (2012) explains, “precarious work results from employment practices that are designed by employers to reduce costs, limit or reduce the permanent workforce, maximise flexibility, and shift risks and uncertainty to workers" (Maiti, 2012, p. 509).

Vives et al. (2020) provide an indicator of precariousness, namely any type of "non-standard or temporary employment" (Vives et al., 2020, p. 1035). Maiti (2012) define precarious work as "employment with high degrees of uncertainty, insecurity, and instability in economic activities" (p. 509). Olsthoorn (2014) also notes that the notion "precarious" implies a high level of insecurity. He argues that this insecurity is embedded in and hidden within a nonstandard contract, making an employee particularly vulnerable.

Various terms are used to designate insecure employment conditions of academics often used interchangeably, such as academic precariat, casual academics, precarious academics (Slobodskaya, 2018). This terminological diversity is due to the fact that in international research the criterion for non-standard academic labour varies and includes part-time 
employment, fixed-term employment, zero-hour contracts, and contingent employment (UCU, 2018).

In general, in academia, precariat has been commonly associated with those who work parttime and fixed-term (Blackham, 2020). Since the "most common forms [of non-standard academic employment] are fixed-term contracts and part-time contracts" (Lang et al., 2013, p. 7), in this study I focus on part-time and fixed-term employment contracts to explore precariat in UK academia. Furthermore, since the UK statistical agency has recently included hourlypaid and zero-hour contracts into its survey, distribution of these forms of non-standard forms of employment were also analysed.

\section{Non-standard forms of employment}

The debate on labour market segmentation between standard and non-standard forms of employment revolves around the issue of precariousness (da Silva \& Turrini, 2015). To discuss the distinctive features of precarious work, it is important to consider it in comparison with standard working conditions.

First, precarious workers are less protected from economic insecurity and, as Lang and colleagues (2013), emphasise, in time of "changes imposed by the economic crisis, atypical workers are the first to suffer changes to their status and employment relationship" (p. 192). Secondly, temporary, and part-time workers often suffer from the wage inequality. Although in a perfectly competitive market the expectation is that temporary contracts workers receive higher wages, empirical evidence shows the existence of a wage premium for permanent employment (see Blanchard \& Landier (2002) for France; Booth et al. (2002); Brown \& Sessions (2003) for the United Kingdom). In the US, there is growing evidence that most women in "flexible" employment do not receive an adequate wage and benefits for their work (Vosko, 2006, p. 79). This is due to the "personal problems", such as care for children, other dependents, and voluntary work, that "do not belong in the workplace" (Appelebaum, 2001, p. 29, in Vosko, 2006, p. 73).

One of the explanations for the wage inequality is that permanent "workers earn more because employment protection reduces the outside option of employers" (e.g., Lindbeck \& Snower, 2001; Boeri, 2011), resulting in that permanent workers are both more protected and better paid than "outsiders" who work part-time or on temporary conditions (Lang, Schömann, \& 
Clauwaert, 2013, p. 3). Third, past research suggests that temporary workers suffer not only from a negative wage gap, but also from lower incentives to accumulate skills (da Silva \& Turrini, 2015). Giesecke and Gross (2003) point to the fact that, compared to standard contracts, fixed-term contracts carry a higher risk of subsequent unemployment or another fixed-term contract. Finally, there are other numerous problems associated with being on a fixed-term academic contract that have been identified in past research. Bryson (1999) summarised its main features: lack of recognition and reward, lack of career structure and minimal progress, little or no inclusion into the academic culture, the perception of being “inferior", a lack of security and an inability to plan (Bryson, 2004, p. 201).

There are two different viewpoints concerning the implications of fixed-term and part-time contract employment for workers, offering competing perspectives. The first viewpoint advocates that temporary employment bridges the transition to permanent employment, and is a way of gaining appropriate experience (Wang \& Weiss, 1998). The second position highlights the risks of fixed-term and part-time employment for academics. Precarious academics may lack the opportunity to become well-rounded professionals due to the limited access to professional development needed to generate a profile with the research and management skills and produce a track record of publications. The conditions of the academic precariat are referred to as a trap: the longer individuals stay in precarious employment, the less secure their position becomes (Blackham, 2020). This line of discussion emphasises the inferiority of nonstandard contracts compared to permanent, full-time positions in terms of wage difference, social security, professional development, and career progression opportunities.

A consideration of the two viewpoints is important to emphasise the starting point of the analysis. I am aware of the two alternative positions and take a critical stance to look at both sides of the nonstandard academic work in the UK.

\section{Methodology and methods}

To analyse the insecure conditions of the academic staff in the UK over the six-year period, this study draws on several datasets obtained from the HESA database. Three forms of insecure employment of academic staff, namely fixed-term and part-time contracts, are selected for the analysis for two reasons. First, fixed-term and part-time contracts are prevalent forms of insecure employment in academia (Lang et al., 2013). Secondly, there is no longitudinal 
statistical data available on other forms of non-standard employment contracts. The obtained data for the period from 2014/2015 till 2019/2020 included information on HEI, gender, contract level (professor, other senior, other contract level), mode of employment (full-time, part-time), and terms of employment (fixed-term, open-ended or permanent). Furthermore, a 2019-2020 HESA data set on hourly paid and zero-hour contracts among different groups of academics has been obtained. The data was analysed using descriptive statistics and data visualisation methods.

\section{Results}

\section{Part-time mode of employment}

Table 1 and Figure 1 show that a larger proportion of female academics being employed parttime is consistent over the whole period. Although the number of female academics involved in either research or teaching, or both, has increased from 169545 in 2014 to 200085 in 2020, $55 \%$ of all academic staff employed part-time are females.

Table 1. Employment conditions for 2014-2020 academic year, by gender.

\begin{tabular}{c|c|c|c|c|c}
\hline & \multicolumn{2}{|c|}{ Female } & \multicolumn{2}{c}{ Male } & Total \\
\hline $\mathbf{2 0 1 4 / 1 5}$ & $\mathbf{1 6 9 5 4 5}$ & $\mathbf{4 5 . 0 4 \%}$ & $\mathbf{2 0 6 8 8 0}$ & $\mathbf{5 4 . 9 6 \%}$ & $\mathbf{3 7 6 4 2 5}$ \\
\hline Full-time & 100800 & $40.07 \%$ & 150760 & $59.93 \%$ & 251560 \\
\hline Part-time & 68745 & $55.06 \%$ & 56120 & $44.94 \%$ & 124865 \\
\hline $\mathbf{2 0 1 5 / 1 6}$ & $\mathbf{1 7 4 0 1 0}$ & $\mathbf{4 5 . 3 4 \%}$ & $\mathbf{2 0 9 8 1 5}$ & $\mathbf{5 4 . 6 6 \%}$ & $\mathbf{3 8 3 8 2 5}$ \\
\hline Full-time & 103670 & $40.42 \%$ & 152830 & $59.58 \%$ & 256500 \\
\hline Part-time & 70340 & $55.24 \%$ & 56985 & $44.76 \%$ & 127325 \\
\hline $\mathbf{2 0 1 6 / 1 7}$ & $\mathbf{1 8 0 1 0 5}$ & $\mathbf{4 5 . 7 1 \%}$ & $\mathbf{2 1 3 8 8 0}$ & $\mathbf{5 4 . 2 9 \%}$ & $\mathbf{3 9 3 9 8 5}$ \\
\hline Full-time & 107640 & $40.85 \%$ & 155840 & $59.15 \%$ & 263480 \\
\hline Part-time & 72465 & $55.53 \%$ & 58040 & $44.47 \%$ & 130505 \\
\hline $\mathbf{2 0 1 7 / 1 8}$ & $\mathbf{1 8 6 3 0 5}$ & $\mathbf{4 5 . 9 6 \%}$ & $\mathbf{2 1 9 0 5 5}$ & $\mathbf{5 4 . 0 4 \%}$ & $\mathbf{4 0 5 3 6 0}$ \\
\hline Full-time & 110960 & $41.26 \%$ & 157965 & $58.74 \%$ & 268925 \\
\hline Part-time & 75345 & $55.22 \%$ & 61090 & $44.78 \%$ & 136435 \\
\hline $\mathbf{2 0 1 8 / 1 9}$ & $\mathbf{1 9 2 4 3 5}$ & $\mathbf{4 6 . 3 3 \%}$ & $\mathbf{2 2 2 8 8 5}$ & $\mathbf{5 3 . 6 7 \%}$ & $\mathbf{4 1 5 3 2 0}$ \\
\hline Full-time & 114475 & $41.73 \%$ & 159835 & $58.27 \%$ & 274310 \\
\hline Part-time & 77960 & $55.29 \%$ & 63050 & $44.71 \%$ & 141010 \\
\hline $\mathbf{2 0 1 9 / 2 0}$ & $\mathbf{2 0 0 0 8 5}$ & $\mathbf{4 6 . 8 2 \%}$ & $\mathbf{2 2 7 2 9 5}$ & $\mathbf{5 3 . 1 8 \%}$ & $\mathbf{4 2 7 3 8 0}$ \\
\hline Full-time & 118445 & $42.21 \%$ & 162170 & $57.79 \%$ & 280615 \\
\hline Part-time & 81640 & $55.63 \%$ & 65125 & $44.37 \%$ & 146765 \\
\hline
\end{tabular}


The overall number of academics has changed from 376425 in 2014/2015 to 427380 in 2019/2020 academic years, with a slightly larger increase in the number of female academics (see Table 1). Interestingly, the pattern of full-time employment has slightly changed to benefit female academics. Specifically, the proportion of females has raised from $40 \%$ in 2014/2015 academic year to $42 \%$ in 2019/2020, whereas for males for the same period figures changed from $60 \%$ to $58 \%$ (see Figure 1).

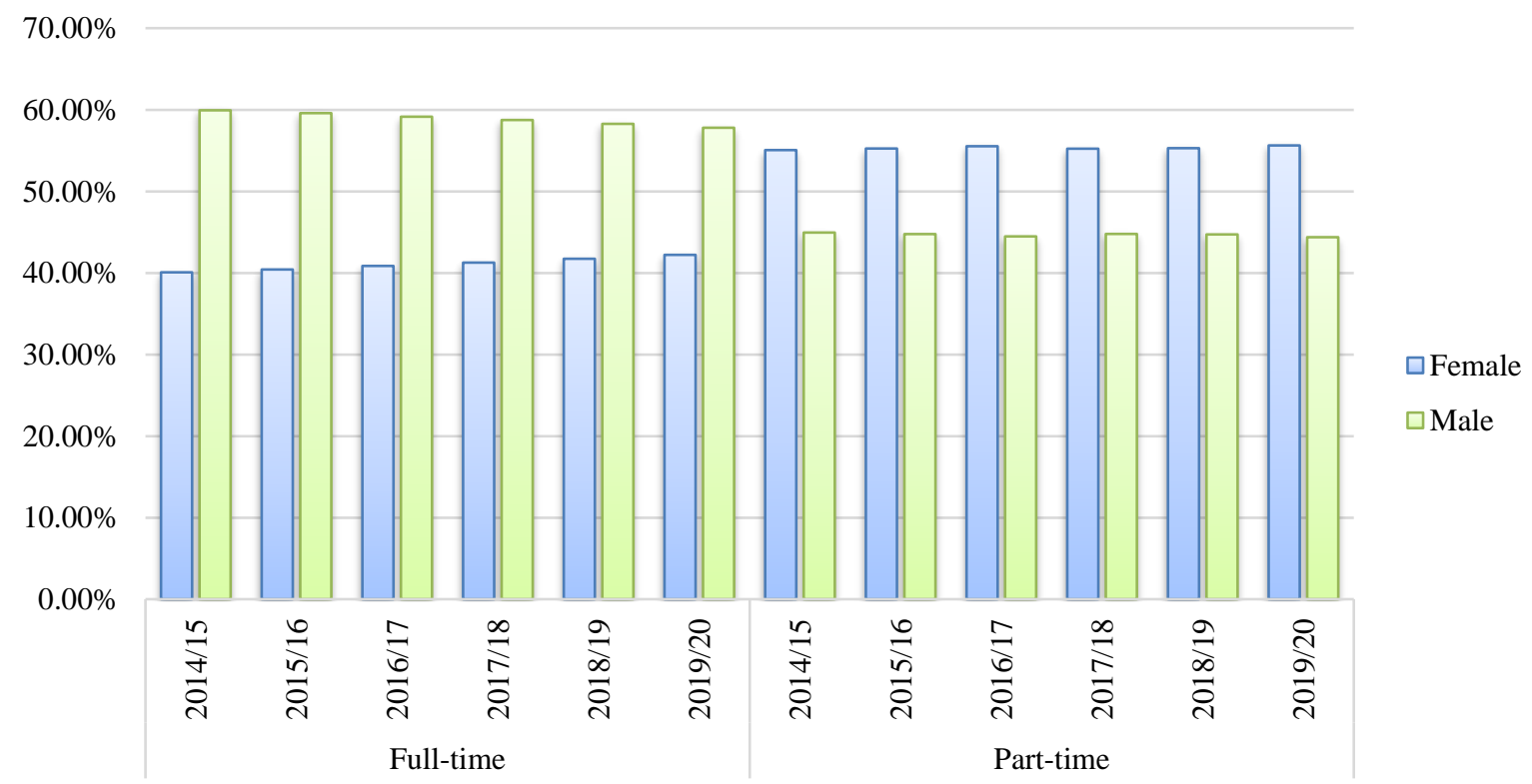

Figure 1. Part time and full-time employment by gender.

A distribution of part-time employment across three contacts levels (professor, senior academic, and other contracts) shows that the part-time phenomenon is predominant among male academics on senior position, whereas non-senior part-time contracts are more prevalent among female academics. Yet, an increase in the proportion of part-time female academics and a decrease of male academics at position of a senior level can be observed over the period between 2014/2015 and 2019/2020 (Figure 2). 


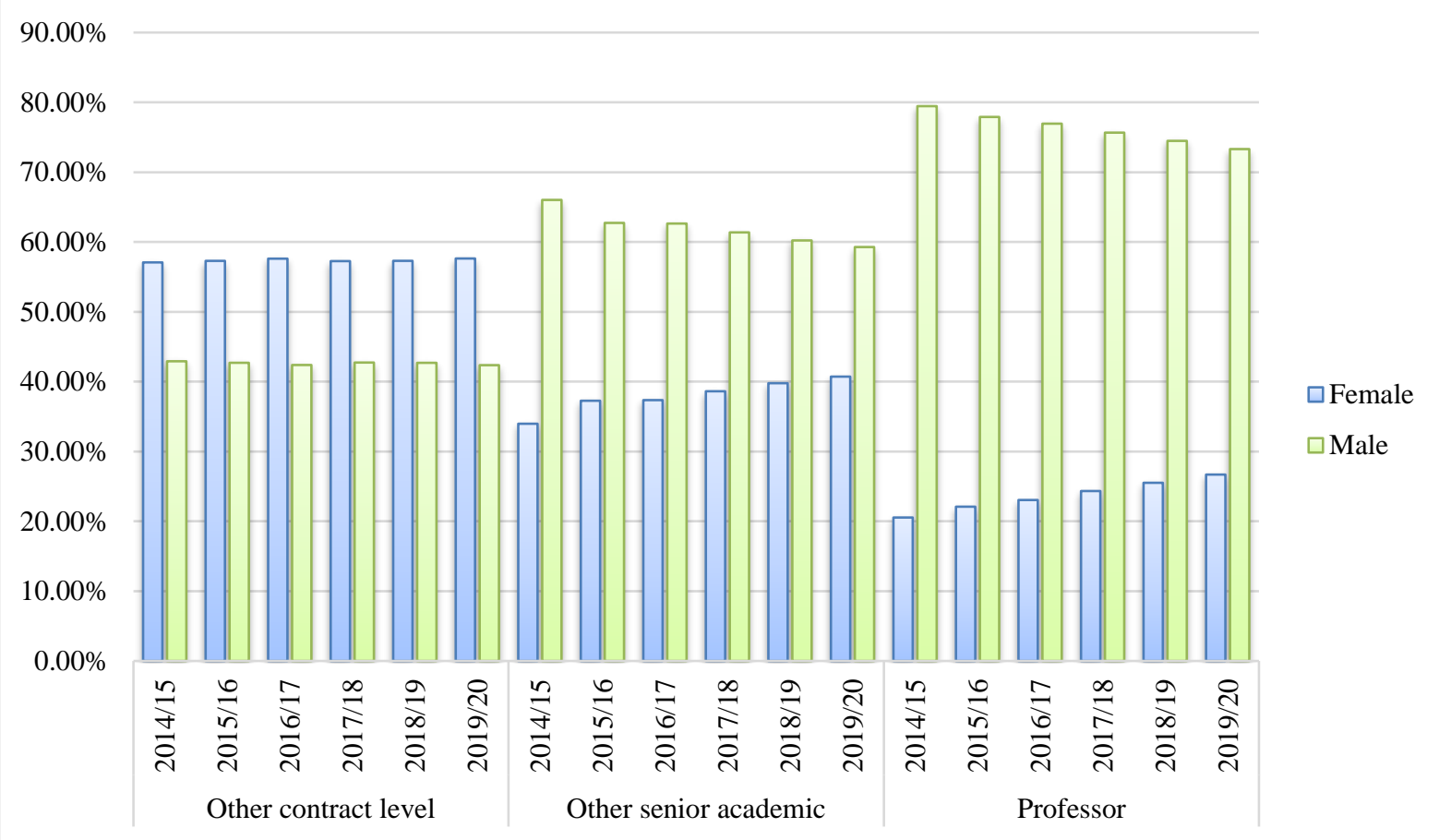

Figure 2. Part- time employment by the contract level and gender.

A closer look at the 2019/2020 academic year shows that distribution of part-timeness across three contact levels shows dramatic difference between female $(6 \%)$ and male $(13 \%)$ professors. Gender difference also exists among academics with no senior position, especially those employed part-time (Table 2). It can be noticed that around $92 \%$ of female academics do not hold a senior position, and 39\% of them work part-time. For their male counterparts these figures are $84 \%$ and $25 \%$ respectively.

Table 2. Employment conditions by contract level and terms of employment, 2019-2020 academic year.

\begin{tabular}{c|c|c}
\hline & Female & Male \\
\hline Professors & $\mathbf{5 . 8 4 \%}$ & $\mathbf{1 3 . 2 2 \%}$ \\
\hline Full-time & $4.63 \%$ & $10.31 \%$ \\
\hline Part-time & $1.20 \%$ & $2.91 \%$ \\
\hline Other senior academics & $\mathbf{2 . 0 9 \%}$ & $\mathbf{2 . 8 6 \%}$ \\
\hline Full-time & $1.90 \%$ & $2.60 \%$ \\
\hline Part-time & $0.20 \%$ & $0.25 \%$ \\
\hline Other contracts & $\mathbf{9 2 . 0 7 \%}$ & $\mathbf{8 3 . 9 2 \%}$ \\
\hline Full-time & $52.67 \%$ & $58.43 \%$ \\
\hline Part-time & $39.40 \%$ & $25.49 \%$ \\
\hline Total & $\mathbf{1 0 0 . 0 0 \%}$ & $\mathbf{1 0 0 . 0 0 \%}$ \\
\hline
\end{tabular}


Visualisation of part-time employment among academics with different employment functions (teaching, research, or both) shows that predominantly a female academics, especially those with research only function work part-time (Figure 3).

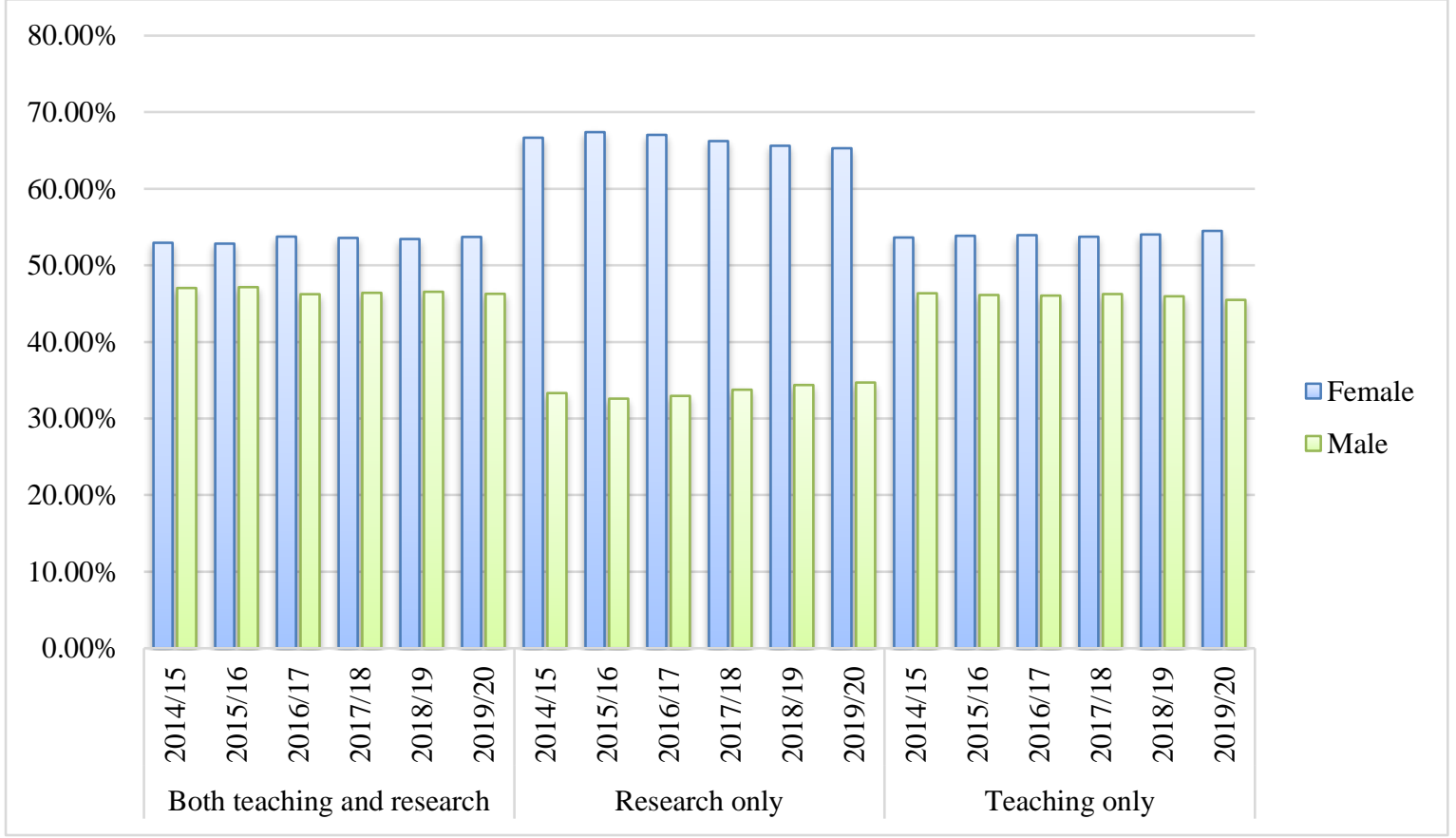

Figure 3. Part- time employment by the academic function and gender.

The data above shows the distributions of part-time employment among female and male academics with different modes and terms of employment, and across three academic employment functions. The first thing to note from the distribution of part-timeness is that there is no apparent evidence that average precariat increased during the analysed period. Indeed, if anything there is some indication that while part-time employment remains the same, while full-time employment slightly increased for female and slightly decrease for male academics.

However, decomposition of data provides a support of the well-known discussion on gender precariat, confirming a predominance of part-timeness among female academics over the considered period. As Figures 2 and 3 show, female academics on non-senior positions and those with research only function still represent the majority from the total part-time staff.

\section{Fixed-term employment}

Examination of terms of employment among UK academics shows that the proportion of male academics out of those who work full-time fixed-term contract is higher than for their female 
colleagues (for 2019/2020 academic year these numbers are 56\% compare to around 44\% respectively). These numbers are consistent over the whole period (Figure 4).

It is worth noting a small decrease in the percentage for male academics working fill-time on a fixed-term contract from $56.3 \%$ to $55.7 \%$, and an increase of female academics working parttime on a fixed-term contract from $53 \%$ to $54 \%$ from 2014/2015 to 2019/2020 academic year.

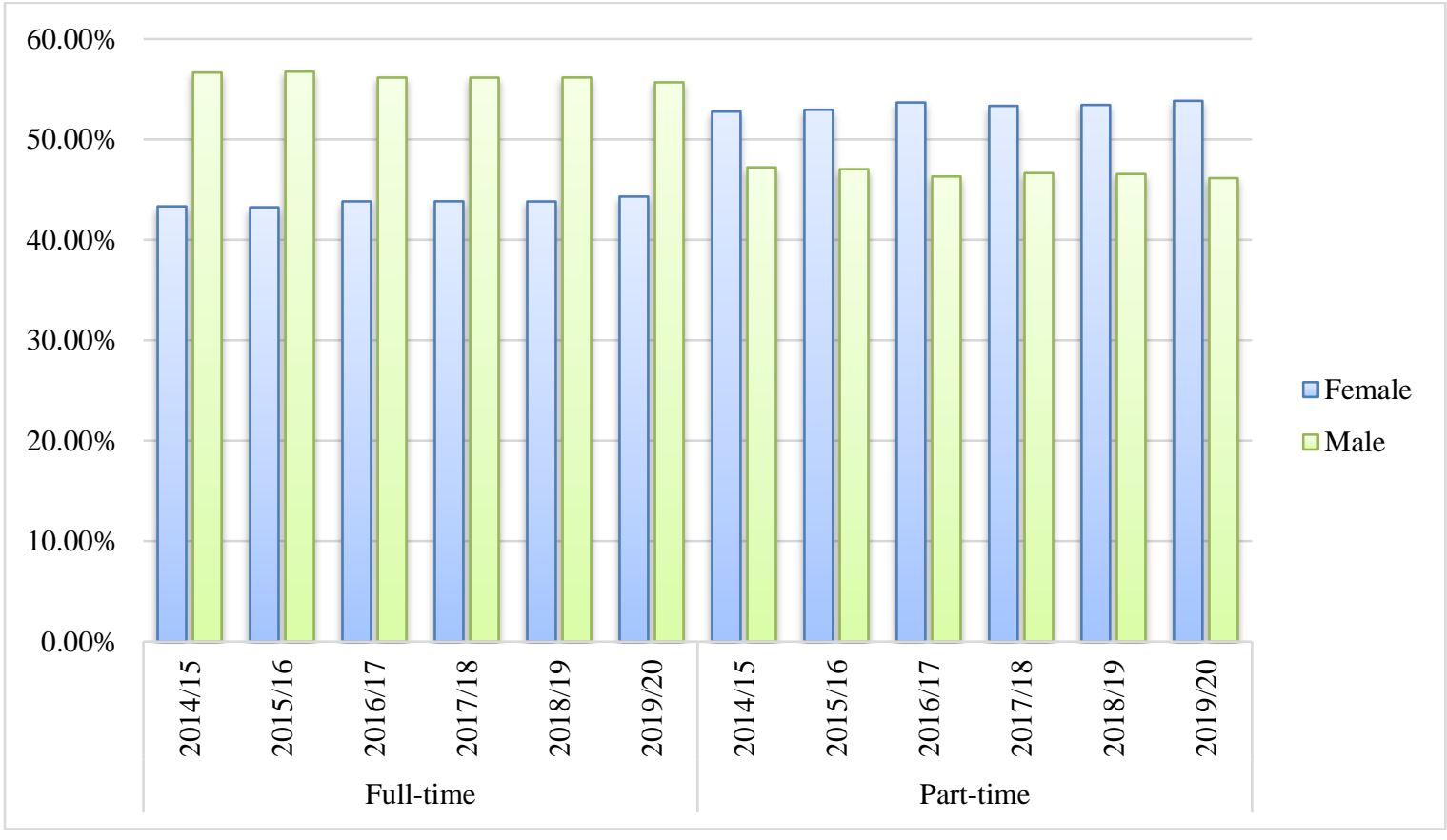

Figure 4. Full-time academics, by terms of employment and gender.

Although there is evidence that the share of female employees in academia has increased, for a large proportion of women employment conditions are insecure. However, despite the male academics holding more full-time and permanent positions, data shows that precariousness is widespread for both sexes.

Distribution of fixed-term contracts by the mode of employment and a seniority of academic position in 2019/2020 academic year is presented on Table 3 and Figure 5.

Table 3. Fixed-term employment by mode of employment and gender, 2019/2020 academic year.

\begin{tabular}{l|c|c|c|c|c}
\hline & \multicolumn{2}{|c|}{ Female } & \multicolumn{1}{c|}{ Male } & Total \\
\hline Other contract level & $\mathbf{6 8 7 2 0}$ & $\mathbf{9 8 . 3 8 \%}$ & $\mathbf{6 9 2 6 0}$ & $\mathbf{9 5 . 9 3 \%}$ & $\mathbf{1 3 7 9 8 0}$ \\
\hline Full-time & 30265 & $43.33 \%$ & 37785 & $52.33 \%$ & 68050 \\
\hline Part-time & 38455 & $55.05 \%$ & 31475 & $43.59 \%$ & 69930 \\
\hline
\end{tabular}




\begin{tabular}{c|c|c|c|c|c}
\hline $\begin{array}{l}\text { Other senior } \\
\text { academic }\end{array}$ & $\mathbf{5 7 5}$ & $\mathbf{0 . 8 2 \%}$ & $\mathbf{7 9 5}$ & $\mathbf{1 . 1 0 \%}$ & $\mathbf{1 3 7 0}$ \\
\hline Full-time & 455 & $0.65 \%$ & 630 & $0.87 \%$ & 1085 \\
\hline Part-time & 120 & $0.17 \%$ & 165 & $0.23 \%$ & 285 \\
\hline Professor & $\mathbf{5 6 0}$ & $\mathbf{0 . 8 0 \%}$ & $\mathbf{2 1 4 5}$ & $\mathbf{2 . 9 7 \%}$ & $\mathbf{2 7 0 5}$ \\
\hline Full-time & 135 & $0.19 \%$ & 360 & $0.50 \%$ & 495 \\
\hline Part-time & 425 & $0.61 \%$ & 1785 & $2.47 \%$ & 2210 \\
\hline
\end{tabular}

An equal proportion of female and male academics who do not have a professor or other senior position are employed on a fixed-term condition. However, a relatively larger number of male professors is employed fixed-term, both full-time and part-time, compare to their female colleagues.

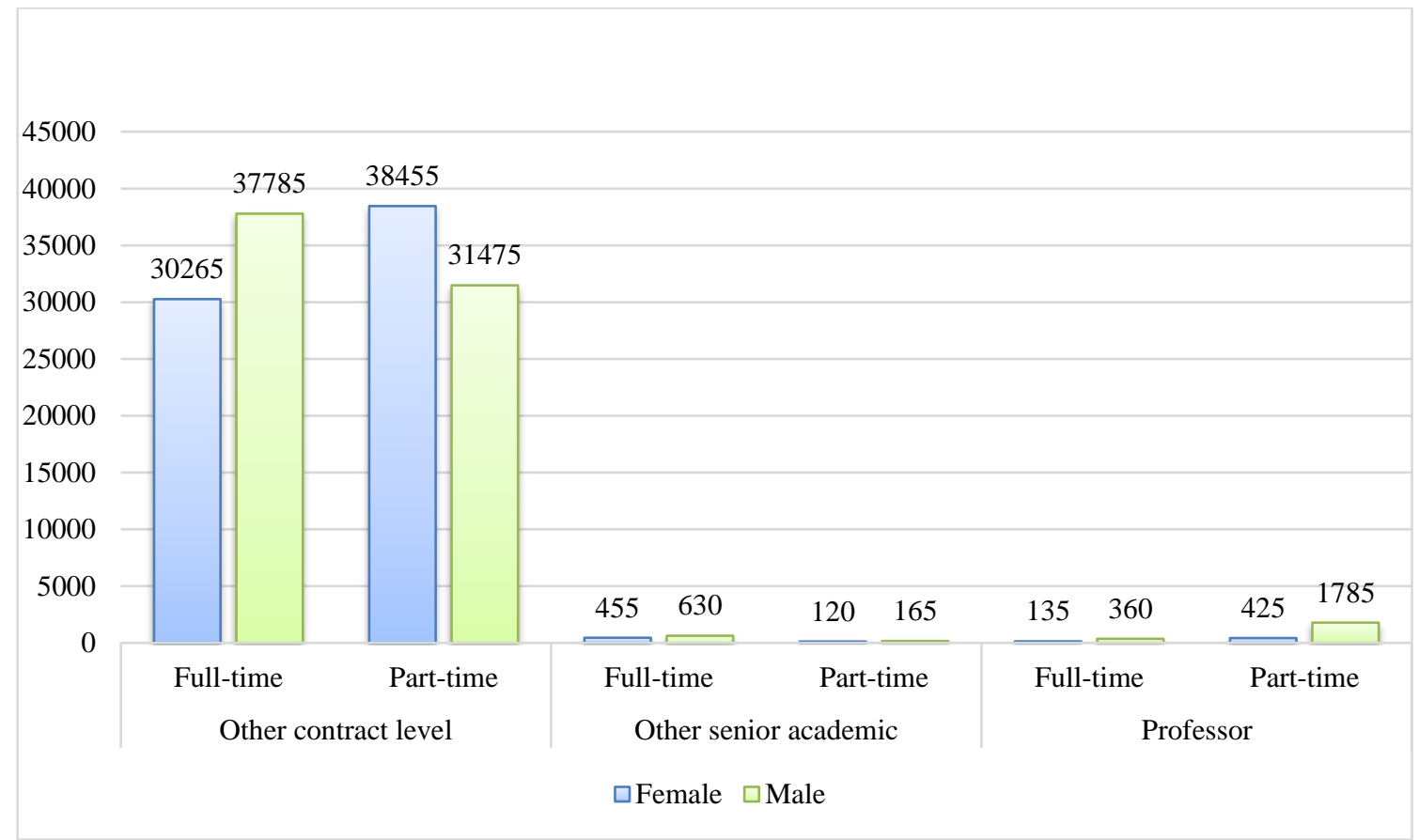

Figure 5. Fixed-term employment by mode of employment and gender.

\section{Hourly-paid and zero-hours employment}

In 2017-2018, HESA first started collecting data on hourly-paid and zero-hour contracts. Blackham (2020) reported that in 2017/2018 academic year, 3.1\% (6520) were on zero-hour contracts, $13.4 \%(28,450)$ were on hourly-paid contracts, and $33 \%(70,945)$ were employed on fixed-term contracts, though these numbers were not mutually exclusive (Blackham, 2020). 
Table 5. Hourly paid and salaried employment contracts for all modes of employment, $2019 / 2020$

\begin{tabular}{l|c|r|r|r|r}
\hline & Female & & Male & & Total \\
\hline Hourly paid & $\mathbf{1 5 3 5 0}$ & $\mathbf{1 4 . 7 4 \%}$ & $\mathbf{1 4 9 2 0}$ & $\mathbf{1 2 . 5 6 \%}$ & $\mathbf{3 0 2 7 0}$ \\
\hline Fixed-term contract & 9430 & $9.05 \%$ & 9260 & $7.80 \%$ & 18690 \\
\hline Open-ended/permanent & 5920 & $5.68 \%$ & 5660 & $4.77 \%$ & 11580 \\
\hline Salaried & $\mathbf{8 8 7 9 5}$ & $\mathbf{8 5 . 2 6 \%}$ & $\mathbf{1 0 3 8 4 5}$ & $\mathbf{8 7 . 4 4 \%}$ & $\mathbf{1 9 2 6 4 0}$ \\
\hline Fixed-term contract & 27040 & $25.96 \%$ & 28440 & $23.95 \%$ & 55480 \\
\hline Open-ended/permanent & 61755 & $59.30 \%$ & 75405 & $63.49 \%$ & 137160 \\
\hline & & $\mathbf{1 0 0 . 0 0}$ & & & $\mathbf{2 0 2 9 1 0}$ \\
\hline
\end{tabular}

The numbers show that for both modes of employment, full and part-time, approximately the same percent of male and female academics employed on hourly paid conditions. A slightly larger proportion of female academics (15\%) employed on salaried conditions.

Deconstruction of hourly paid contracts by terms of employment, however, shows that while the proportion of part-time employment on an hourly paid basis is equal for both sexes, there are slightly more male academics who work full-time on an hourly paid contract. among male academics (640 male and 550 female academics in 2019/2020).

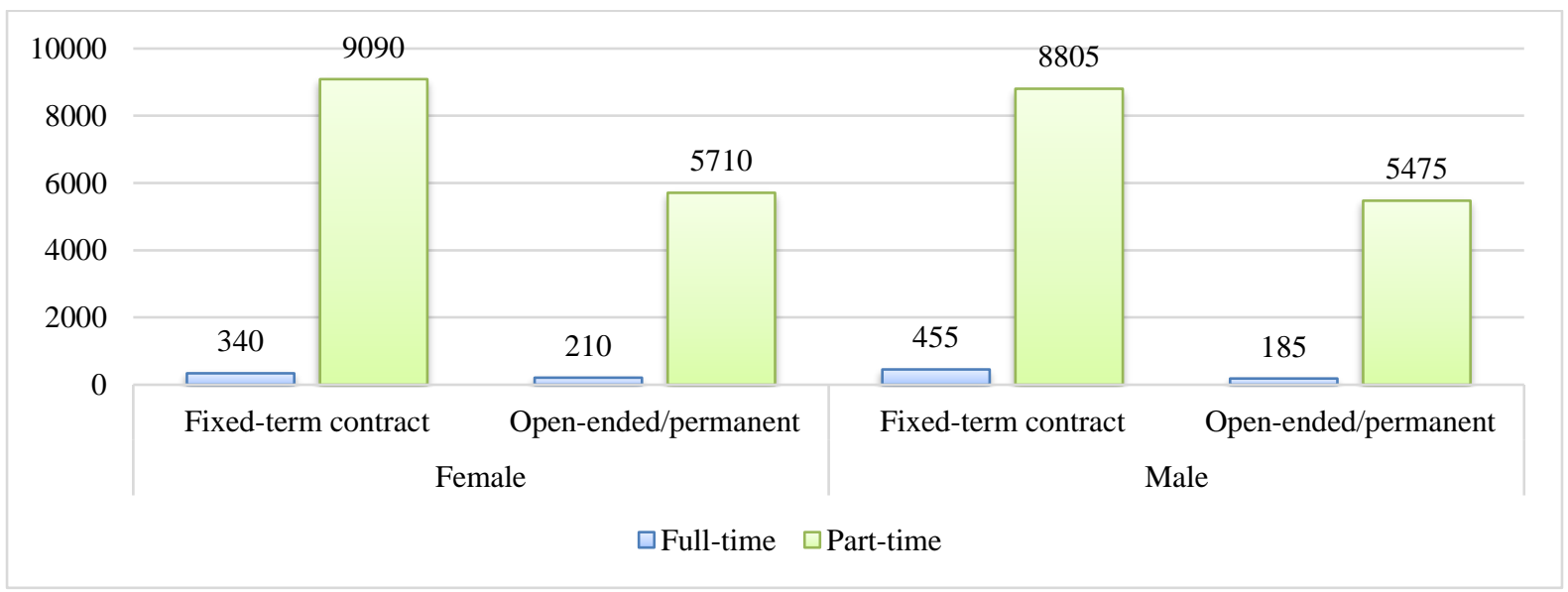

Figure 6. Hourly-paid employment contracts, by mode of employment and gender.

The next table shows a distribution of zero-hour contracts in 2019/2020 by mode, terms of employment and gender. 
Table 6. Zero-hour employment contracts, 2019/2020 academic year.

\begin{tabular}{l|c|c|c|c|c}
\hline & \multicolumn{2}{|c|}{ Female } & Male & \multicolumn{2}{c}{ Total } \\
\hline Fixed-term contract & $\mathbf{5 3 5}$ & $\mathbf{2 9 . 0 8 \%}$ & $\mathbf{4 2 5}$ & $\mathbf{2 6 . 9 0 \%}$ & $\mathbf{9 6 0}$ \\
\hline Full-time & 10 & $0.54 \%$ & 10 & $0.63 \%$ & 20 \\
\hline Part-time & 525 & $28.53 \%$ & 415 & $26.27 \%$ & 940 \\
\hline Open-ended/permanent & $\mathbf{1 3 0 5}$ & $\mathbf{7 0 . 9 2 \%}$ & $\mathbf{1 1 5 5}$ & $\mathbf{7 3 . 1 0 \%}$ & $\mathbf{2 4 6 0}$ \\
\hline Full-time & 90 & $4.89 \%$ & 65 & $4.11 \%$ & 155 \\
\hline Part-time & 1215 & $66.03 \%$ & 1090 & $68.99 \%$ & 2305 \\
\hline Grand Total & $\mathbf{1 8 4 0}$ & $\mathbf{1 0 0} \%$ & $\mathbf{1 5 8 0}$ & $\mathbf{1 0 0 \%}$ & $\mathbf{3 4 2 0}$ \\
\hline
\end{tabular}

Among 3420 academics employed on a zero-hour contract in 2019/2020 academics year, there are $54 \%$ of female and $46 \%$ male academics. Among those working on a zero-hour contract, $29 \%$ of females and $27 \%$ of males were working on temporary contracts, and $71 \%$ and $73 \%$ of female and male academics respectively, on a permanent contract (see Figure 7 for absolute numbers).

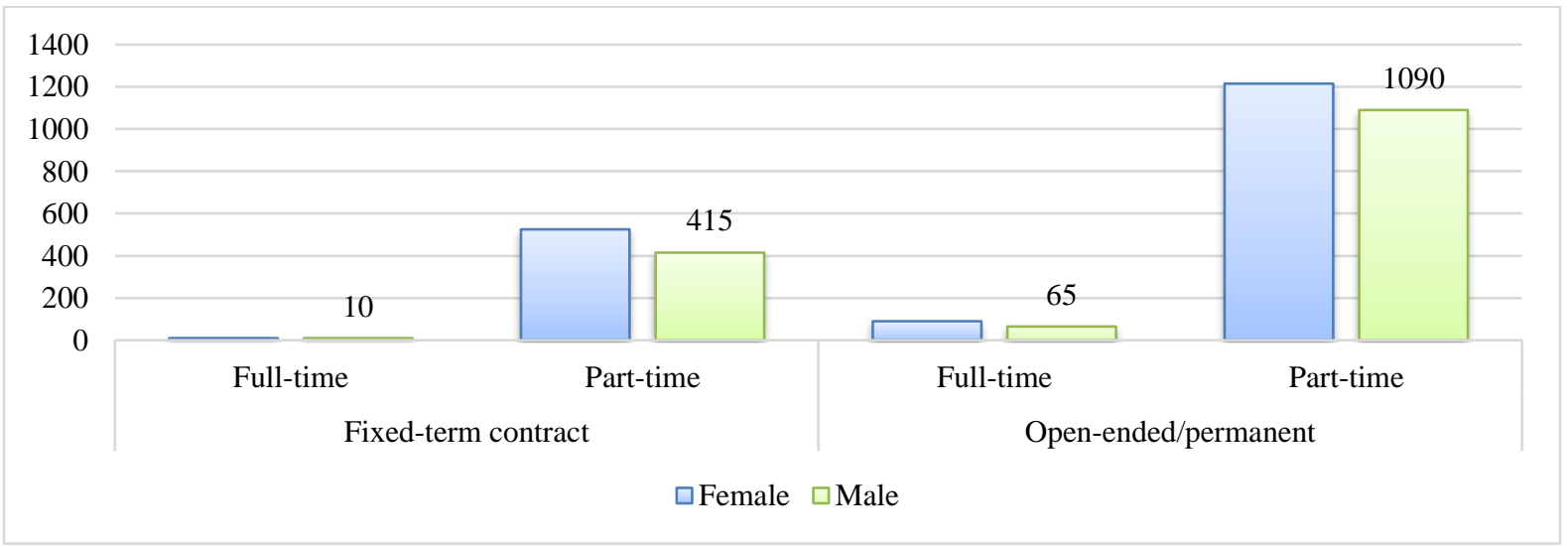

Figure 7. Zero-hour employment contracts, by terms of employment, contract type and gender.

Data shows that by 2019/2020, the use of zero-hour contracts had declined as HEIs were moving away from this form of contract. However, although zero-hour contracts are in decline, other precarious work arrangements are still widespread in UK HE.

\section{Discussion}

The first aim of the study was to analyse HESA data for the period from the 2014/2015 to 2019/2020 academic years on the distributions of part-time employment among female and male academics. Data suggests that for the considered period, there was no rise in part-time 
employment compared to full-time employment. Furthermore, the general picture is that fulltime employment has slightly increased for females and slightly decreased for male academics.

Consideration of part-timeness among academics employed on different contract modes and terms of employment, across three academic functions, provides a nuanced understanding of the situation. Part-time employment is prevalent among male academics in senior positions, and among female academics in non-senior positions. For the considered period, there is an increase of female and a decrease of male academics employed part-time at a senior level. However, when considering just professors, in the 2019/2020 academic year, $6 \%$ of female, compared to $13 \%$ of male professors, were employed part-time. In terms of academic function, female academics with research only remit, predominantly work part-time.

Regarding the term of employment, the proportion of males employed full-time and on a fixedterm contract is higher than that of female academics. This trend is consistent for the whole considered period. Yet, it can be noticed that the proportion of males employed on full-time and fixed-term contracts has slightly decreased, whilst the proportion of females increased.

Approximately the same proportion of non-senior males and females are employed on a fixedterm contract. An equal number of academics of both genders, working full-time and part-time, are on hourly pay. However, while the proportion of part-time employment on an hourly paid basis is equal for males and females, in the 2019/2020 academic year, slightly more males were employed full-time on an hourly paid basis.

It should be noted that there is considerable research on gender inequality in academia which offers a range of explanations. For example, it has been argued that the academic profession is gendered due to the larger number of opportunities offered to men (Bryson \& Barnes; 2000; Bryson, 2004). On the other hand, there is also an opinion that female academics express higher preference towards part-time and fixed-term employment (Bryson, 2004). However, the analysis conducted in this study showed that both, male and female academics are affected by precariat. There is a slightly larger proportion of women in UK academia than men, and the share of women in insecure positions is high on fixed-term and part-time contracts. Yet, despite the male academics holding more full-time and permanent positions, data shows that precariousness is widespread for both genders.

Opinions on why a larger share of female academics are employed on part-time and fixed-term contracts have been offered in the past (see Beatson, 1995; Casey, 1988). One of them is that 
part-time, flexible employment provides additional opportunities for female academics to enter the labour market, and to balance their commitments and childcare responsibilities. Furthermore, it is argued that the positive side of part-time, fixed-term contracts, supported by friendly policies (Simkin \& Hillage, 1992), allow female academics to voluntarily select fewer hours and opt for a greater flexibility around their commitments. However, little evidence suggests that only female academics are likely to prefer non-standard contracts (Gallie et al., 1998). Indeed, as analysis showed, temporary and fixed-term conditions are as common for male academics as they are for females.

The pragmatic reasons for part-timeness may be also explained by the burden of responsibilities experienced by academics, that force them to select a more flexible yet insecure job in the first place. Furthermore, limited access to professional development opportunities with less secure working conditions may create a wall for young academics who are ready to move to more stable employment.

On the other hand, not all non-standard contracts are undesirable. First, flexible forms of employment may be preferred by individuals due to their conditions, for male and female academics. Secondly, as mentioned earlier, part-time, fixed-term and zero-hour contracts may establish a route to a desirable job in the labour market. However, the benefits of a precarious contract depend on the further development of governmental and HEI policies towards temporary, fixed-term and zero-hour contracts in academia. Such policies will determine whether academics are offered the benefits of flexibility and freedom, or are stepping into a trap of precarity (Büchtemann\& Quack, 1989; Natti, 1993). For the UK, the development of the precariat may take different routes and further research that tracks and documents its evolution and effect is important.

\section{Limitations}

The study findings are limited by the focus on four forms of precarious contrast prevalent in the UK, namely, part-time, fixed-term, hourly-paid and zero-hour contracts. Thus, in this study I did not consider some forms of temporary work, such as subsidized employment contracts and on-call employment, which have been identified as particularly disadvantaged. 


\section{Acknowledgement}

I want to thank my colleague Bernardo Eugenio Pincheira Sarmiento for our helpful discussions on the limitations of HESA data at the early stage of work on this paper.

\section{References}

Blackham, A. (2020). Unpacking precarious academic work in legal education. The Law Teacher, 54(3), 426-442.

Bryson, C. (2004). The consequences for women in the academic profession of the widespread use of fixed term contracts. Gender, Work \& Organization, 11(2), 187-206.

Bryson, C., \& Barnes, N. (2000). The Casualisation of Employment in Higher Education in the United Kingdom. In M. Tight (Ed.), Academic Work and Life: What It is to be an Academic, and How This is Changing (International Perspectives on Higher Education Research, Vol. 1). Bingley: Emerald Group Publishing Limited.

Burchell, B.J. (1994). 'Who is Affected by Unemployment? Job Insecurity and Labour Market influences on Psychological Health.' in Gallie, D., Marsh, C., and Vogler, C. (eds.) Social Change and the Experience of Unemployment. Oxford: Oxford University Press.

Crew, T. (2020). Precarity. In Higher Education and Working-Class Academics (pp. 45-67). Palgrave Pivot, Cham.

Higher Education Statistical Agency. (2020). Higher Education Staff Statistics: UK, 2019/2020

Ivancheva, M. (2015). The Age of Precarity and the New Challenges to the Academic Profession. Studia Europaea,(1), 39-47.

Lang, C., Clauwaert, S., \& Schömann, I. (2013). Working time and atypical forms of employment contracts in times of crisis: recent reforms in the Member States. Social Developments in the European Union, 191-215.

Loveday, V. (2018). The neurotic academic: Anxiety, casualisation, and governance in the neoliberalising university. Journal of Cultural Economy, 11(2), 154-166. 
Maiti, D. (2013). Precarious work in India: Trends and emerging issues. American Behavioral Scientist, 57(4), 507-530.

Standing, G. (2011). The Precariat: The New Dangerous Class. London: Bloomsbury Publishing.

Standing, G. (2014). The precariat. Contexts, 13(4), 10-12.

Slobodskaya, A. V. (2018). Precariatization of researchers and teachers of higher education: the formation of an academic precariat. Manuscript, 7(93), 106-110.

University and Colleges Employers' Association. (2020). UCEA Expresses Disappointment on Continued Misleading Use of Atypical Contracts Data. Online. Retrieved January 24, 2022, from https://www.ucea.ac.uk/en/news/index.cfm/21nov16

Vives, A., Gonzalez Lopez, F., \& Benach, J. (2020). Measuring precarious employment: type of contract can lead to serious misclassification error. Annals of work exposures and health, 64(9), 1035-1038.

Vosko, L. F. (Ed.). (2006). Precarious employment: Understanding labour market insecurity in Canada. McGill-Queen's Press-MQUP. 
